\title{
IMPROVEMENT IN PAIN CONTROL WITH WOUND CATHETER AFTER LIVER TRANSPLANTATION SURGERY
}

\author{
Femenía Price F., Cabedo Vidal X., Argente Navarro MP., López Andújar R*, Moya Herraiz A*. \\ Hospital Universitari i Politécnic La Fe, Dept of Anaesthesiology \& Pain Medicine, Dept of General Surgery*. Valencia, Spain
}

\section{BACKGROUND AND GOAL OF STUDY}

Local anaesthetics have become increasingly popular for management of surgical pain after open hepatic surgery. In addition to providing good analgesia, local anaesthetic wound infiltration is safe and low cost. The benefit of this technique remains controversial related to the position of the catheter. Therefore, the analgesic efficacy of continuous local anaesthetic instillation after liver transplantation surgery remains unknown. The aim of this study was to assess the analgesic efficacy of continuous wound instillation of ropivacaine in patients undergoing liver transplantation surgery with the catheter placed within the musculo-fascial layer of the abdominal wall.

\section{MATERIAL AND METHODS}

All liver transplant patients from January 2015 to November 2015 were collected. Since June 2015 a new analgesic protocol is developed to post-liver transplant based on continuos local anaesthetic infiltration by wound catheters with rescue pain by bolus of morphine. So we can compare the new protocol (protocol B) versus the management standard based in intravenous morphine (protocol A)

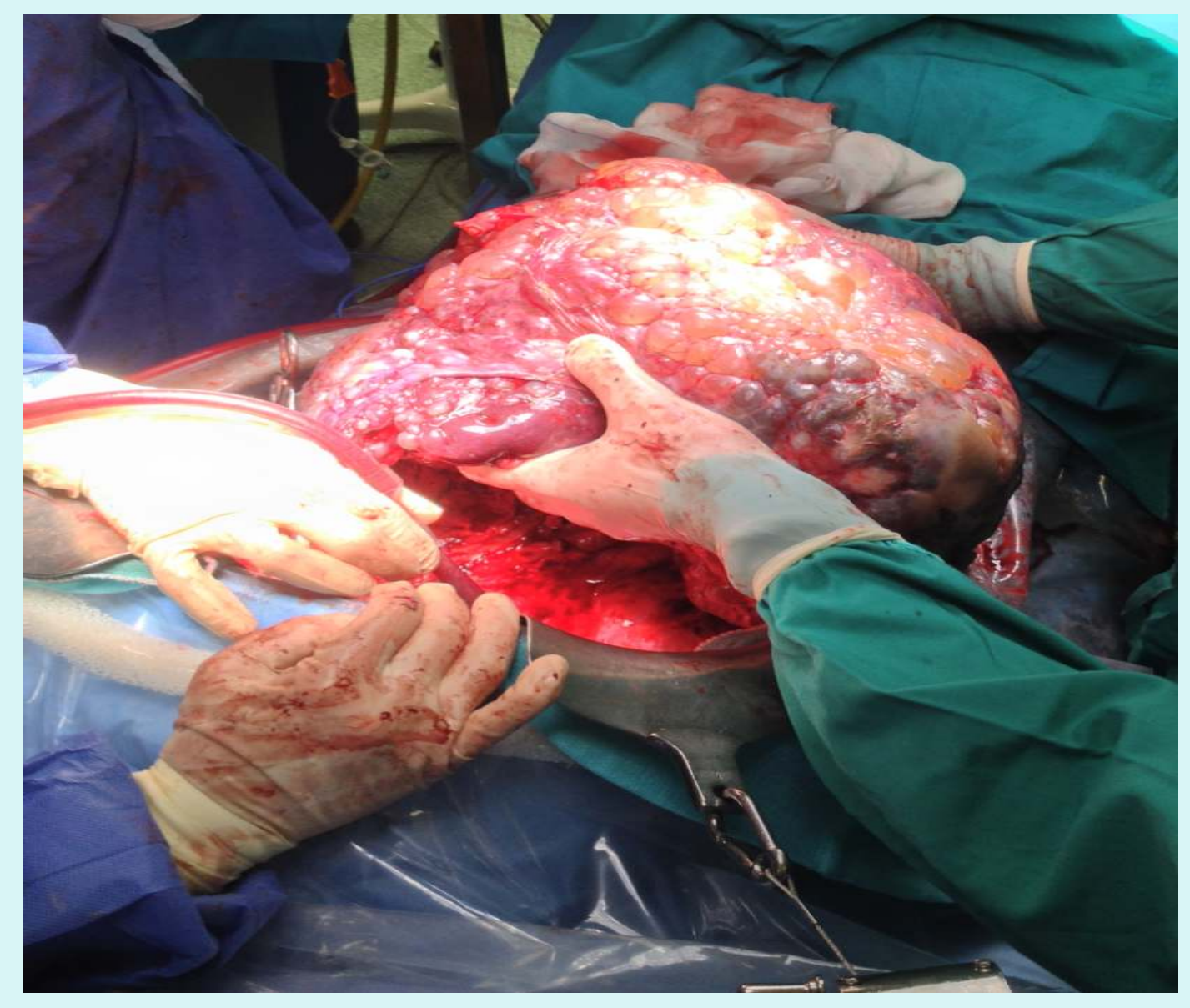

\section{RESULTS}

In the study period they were recorded 83 liver transplants. 58 patients were included in the protocol A (estandarized of intravenous morphine) $86,2 \%$ male, average age was 56.2 years (SD 12.5) and avarage weight $72.7 \mathrm{Kg}$ (SD 14.4). 25 patients were included en protocol B (catheher instillation), 80\% male, average age was 56.3 years (SD 7.5) and avarage weight $80.9 \mathrm{Kg}$ (SD 13.1).

\begin{tabular}{|l|c|c|}
\hline & Patients Protocol A & Patients Protocol B \\
\hline Visual analogue scale (VAS) & 3.8 (SD 2.6) & 2.8 (SD 2.6) \\
\hline Stayed in the critical care unit & 3.7 days (SD 5,3) & 3.3 days (SD 2.4) \\
\hline Rescue dose of morphine used during the first 72 hours postoperative & $28.4 \mathrm{mg}$ (SD 11.7) & $19,1 \mathrm{mg}$ (SD 4,6) \\
\hline
\end{tabular}

\section{CONCLUSION}

A better pain control, decreased stayed in critical care unit and reduced morphine consumption were detected in patients included in new protocol based on continuos local anaesthetic infiltration by wound catheters with rescue pain by bolus of morphine in liver transplant patients. These improvements in pain control patient could save costs.

\section{References:}

Raines S, Hedlnd C, Franzon M, Lllieborg S, Kelleher G, Ahlen K. Ropivacaine for continuous wound infusion for postoperative pain management: a systematic review and meta-analysis of randomized controlled trials. Eur Surg Res. 2014:53(1-4):43-60. doi: 10.1159/000363233. Epub 2014 Jul 23.

2 Chan SK, Lai PB, Li PT, Wong J, Karmakar MK, Lee KF, Gin T. The analgesic efficacy of continuous wound instillation with ropivacaine after open hepatic surgery. Anaesthesia. 2010 Dec;65(12):1180-6. doi: 10.1111/j.1365-2044.2010.06530.x. Epub 2010 Oct 19.

3 Benhamou D, Berti M, Brodner G, De Andre J_Draisci G, Moreno-Azcoita M, Neugebaver EA, Schwenk W, Torres LM, Viel E. Postoperative Analgesic THerapy Observational Survey (PATHOS): a practice pattern study in 7 central/southern European countries. Pain. 2008 May; 136(1-2):134-41. Epub 2007 Aug 20 